\title{
A Surgical Approach to Pediatric Glaucoma
}

\author{
Arif O. Khan
}

Division of Pediatric Ophthalmology, King Khaled Eye Specialist Hospital, PO Box 7191, Riyadh, 11462, Saudi Arabia

\begin{abstract}
Glaucoma in children differs from adult-onset disease and typically requires surgical intervention. However, affected children exhibit a spectrum of disease severity and prospective data guiding the choice of operation are lacking. This article reviews common procedures and a surgical approach to pediatric glaucoma.
\end{abstract}

Keywords: Amblyopia, pediatric glaucoma, surgery.

\section{INTRODUCTION}

While there are several excellent classification schemes [1-6], pediatric glaucoma can be broadly categorized as congenital/infantile, developmental, or secondary (e.g., uveitic, aphakic, angle-closure). Presenting features, differential diagnoses, and surgical considerations differ in young children as opposed to adults or older children. In addition, monogenic mutation more often underlies pediatric glaucoma than adult-onset glaucoma.

Classic clinical findings in younger children include tearing, photophobia, corneal enlargement with Descemet membrane breaks (Haab striae), corneal haze and warping (with resultant astigmatism), conjunctiva inserting anterior to the true limbus, a high flat iris insertion (in congenital cases), increased measured intraocular pressure (IOP), optic nerve cupping, and globe enlargement (buphthalmos) with resultant myopia (Figs. 1, 2). For most congenital/infantile cases diagnosis is straightforward; however, not all classic signs are always present [7]. In addition, conditions that can mimic pediatric glaucoma must always be kept in mind [8]. These include isolated megalocornea, traumatic (forceps) delivery with corneal damage, congenital hereditary endothelial dystrophy, mucopolysaccharidoses, congenital excavations of the optic disc, and high myopia. In particular, congenital hereditary endothelial dystrophy can be misdiagnosed as congenital glaucoma because in some (but not all) infants with congenital hereditary endothelial dystrophy, measured IOP is falsely elevated (Fig. 3) [9].

Monogenic mutation more commonly underlies pediatric glaucoma than adult-onset glaucoma, although most primary congenital/infantile cases worldwide are idiopathic [10]. Recessive mutations in CYP1B1 (On-line Mendelian Inheritance in Man [MIM] *601771) are the most common identifiable cause of primary congenital/infantile glaucoma, particularly in certain consanguineous populations [11]. Although some authors have reported mutations in LTBP2 (MIM *602090) as associated with primary infantile/

*Address correspondence to this author at the Division of Pediatric Ophthalmology, King Khaled Eye Specialist Hospital, PO Box 7191; Riyadh, 11462, Saudi Arabia; Tel: 966-01-482-1234, Ext. 3774;

E-mail: arif.khan@mssm.edu congenital glaucoma, in fact recessive $L T B P 2$ mutations cause a complex anterior segment phenotype with primary megalocornea and secondary lens-related glaucoma rather than primary glaucoma (Fig. 4) [12]. Additional genes that when mutated are associated with pediatric glaucoma include FOXC1 (MIM *601090), PITX2 (MIM *601542), PAX6 (MIM *607108), and others [10]. If the responsible mutation is identified in a given gene for monogenic disease, family genetic counseling can be provided. This is particularly important for CYP1B1-related disease as apparently normal siblings of a baby with obvious primary congenital/infantile from CYP1B1 mutations can in fact harbor the mutations but develop glaucoma at a later age [10].

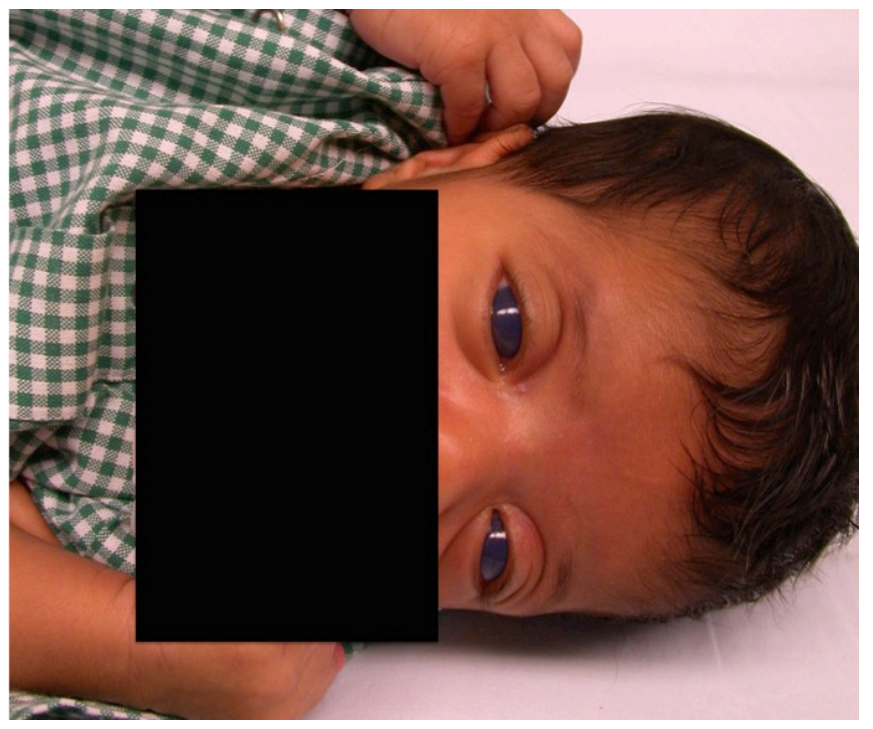

Fig. (1). (Classic signs): Corneal enlargement and haze are classic signs of congenital glaucoma, as seen in this 19-day old girl.

Once the diagnosis of pediatric glaucoma has been established, management is typically surgical. Untreated glaucoma in young children leads to globe enlargement, corneal warping and scarring, optic nerve damage, amblyopia, and in more severe cases, spontaneous retinal detachment [2, 13, 14] (Fig. 5). It is important to remember that a major cause of decreased vision from glaucoma in young children is untreated amblyopia. A child who has surgery that results in corneal clearing, lowering of IOP, 
and/or reversal of optic nerve cupping will still have lifelong poor vision unless early on in life he/she is properly refracted and treated for any associated amblyopia. Unfortunately, studies that emphasize IOP and anatomic outcomes without addressing the issue of amblyopia can consider eyes that are actually legally blind to be surgical successes.

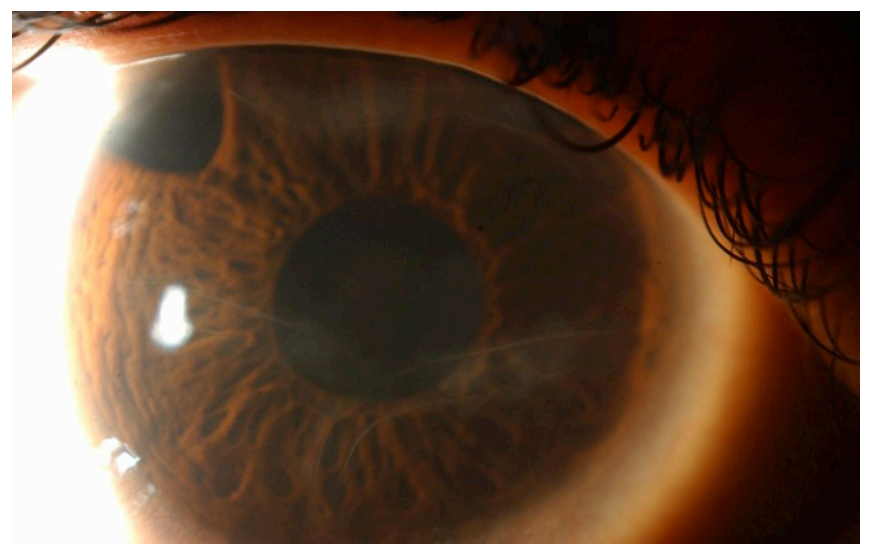

Fig. (2). (Haab's striae): Haab's striae, circumlinear typically horizontal breaks in Descemet's membrane, are a useful confirmatory sign in borderline cases. They can be seen in the right eye of this 5-year-old child whose glaucoma is controlled after superotemporal trabeculectomy with mitomycin-C.

(A)

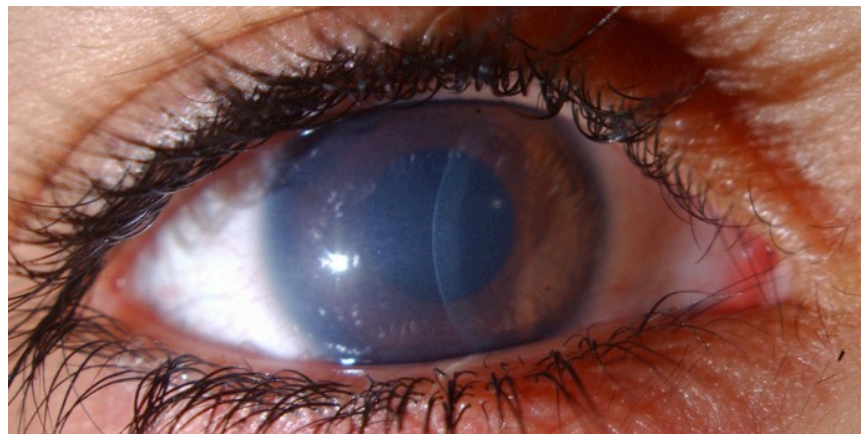

(B)

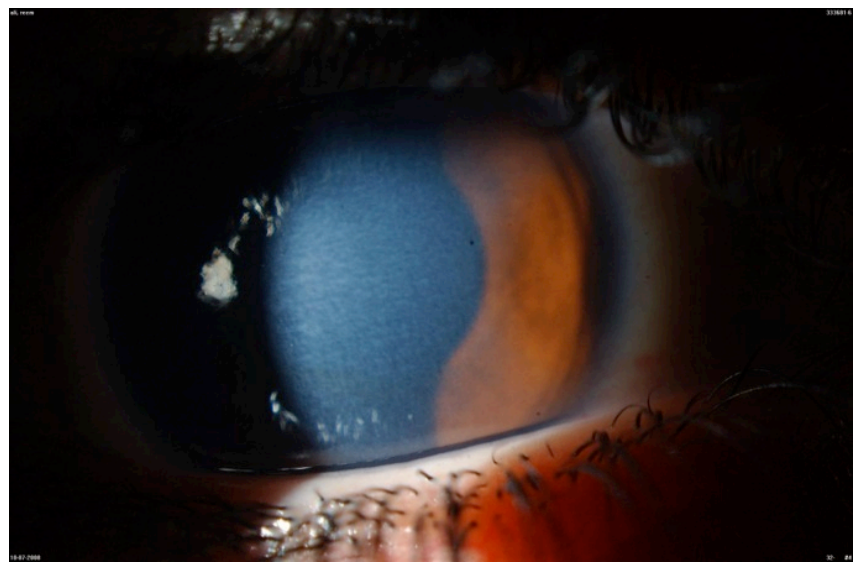

Fig. (3). (CHED): This 6-year-old girl was being treated with antihypertensive drops because of increased measured intraocular pressure. However, the (A) corneal thickness and (B) mosaic corneal haze are very characteristic for congenital hereditary endothelial dystrophy, and there was no ocular enlargement or disc cupping. Genetic testing confirmed recessive SLC4A11 mutations.

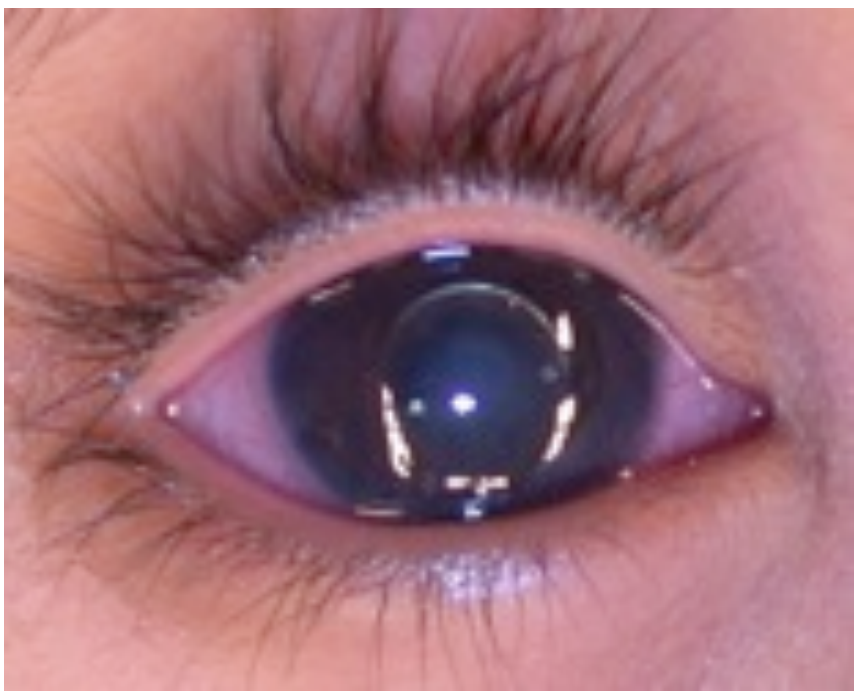

Fig. (4). (LTBP2): This 6-year old boy presented with nausea and vomiting because of acute lens-related glaucoma (crystalline lens in the anterior chamber) and was confirmed to harbor recessive LTBP2 mutations. Note the primary megalocornea $(14 \mathrm{~mm}$ horizontal corneal diameter). In the left eye (not shown) the ectopic crystalline lens was tenting the iris anteriorly.

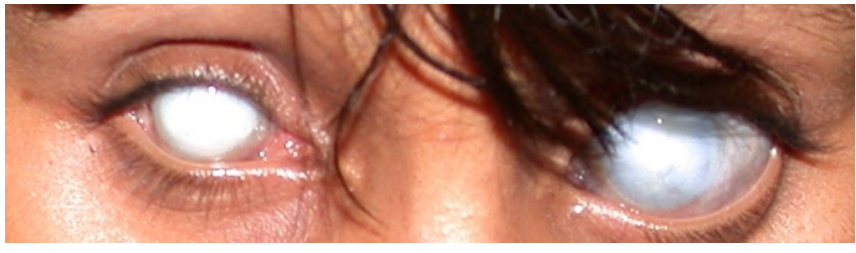

Fig. (5). (Untreated glaucoma): Untreated congenital/developmental glaucoma can lead to severe corneal scarring, buphthalmos, and optic nerve damage. There can be different severities in the two eyes of a single patient, as was the case in this teenage girl.

Prospective comparative data for surgical treatment of pediatric glaucomas are lacking. Moreover, because of a wide potential spectrum of disease severity, differences in pre and post operative management, and different definitions of "success" in existing studies, it can be difficult to draw conclusions from success rates of surgical procedures in published retrospective studies. Thus for a given patient initial (and subsequent) surgical choice needs to be tailored according to the particular patient's phenotype in the context of the surgeon's surgical experience/preferences as well as availability of equipment and adjunctive medication. For primary congenital/infantile glaucoma, the first decision is whether an angle surgery, the classic initial approach, is appropriate or not for a given patient. An affected family member having been successfully treated by angle surgery does not necessarily mean angle surgery is appropriate for a given patient, as different individuals from the same family carrying the same pathogenic mutations can have a large difference in degree of angle malformation and thus in response to angle surgery $[10,15]$. If angle surgery fails or the surgeon decides angle surgery is not appropriate, other options include penetrating filtering surgery (trabeculectomy), non-penetrating filtering surgery (deep sclerectomy), glaucoma drainage devices, and cyclodestructive procedures. 


\section{SURGICAL OPTIONS}

\subsection{Goniotomy}

Goniotomy, the classic initial angle surgery for congenital/infantile glaucoma, refers to the creation an internal cleft in trabecular tissue under direct visualization through the cornea in order to allow access of aqueous humor to Schlemn's canal [16]. Typically this is performed using a specially-designed direct gonioscopic lens and gonitomy lens knife under the operating microscope with the patient's head turned such the desired segment of angle to be treated is brought into view. A sector of the angle is typically treated, and the procedure can be repeated in another sector if needed. Because excellent visualization of the angle is needed, classic gonitomy cannot be performed in the setting of significant corneal scarring and/or haze. Visualization can sometimes be improved by removing corneal epithelium and/or a short course of oral carbonic anhydrase inhibitor; in addition, endoscopic gonitomy is an option in such situations [17-19]. Besides congenital/infantile and early developmental glaucoma, there is also a role for goniotomy in uveitic glaucoma of recent onset [20]. Western series of congenital/infantile and early developmental glaucoma generally report high success rates from single or multiple goniotomies, often over $90 \%$ [21-24]. However, the procedure is much less successful for cases with congenital onset or onset after 2 years old, reported as $30 \%$ in one large Western series when restricted to these ages [22]. Complications are typically related to intraoperative hyphema or intraoperative technique (e.g., iatrogenic crystalline lens trauma). An advantage of goniotomy over many other glaucoma surgical procedures is that it spares the conjunctiva, thus preserving un-operated conjunctiva for future surgical procedures. Although goniotomy is not a typical choice for aphakic glaucoma or open-angle juvenile glaucoma, some authors suggest its use for these diagnoses $[25,26]$. In addition, it has also been suggested that there may be a role for prophylactic goniotomy in selected aniridia patients without glaucoma [27]. One report described the use of Q-switched neodymium:yttrium aluminium garnet (Nd:YAG) laser to perform photodisruptive goniotomy and avoid invasive intraocular surgery [28], but this has not been further studied.

\subsection{Trabeculotomy}

External trabeculotomy [29] is classically the initial procedure of choice for congenital/infantile glaucoma with a scarred or hazy cornea that precludes goniotomy; such severe disease is more common in the Middle East and South Asia [30-32]. The only specialized instrument required for the procedure is the trabeculotome (Fig. 6); other needed instrumentation is standard for ophthalmic microsurgery. After the overlying conjunctiva is dissected, Schlemn's canal is opened (either directly or underneath a scleral flap) and is cannulated with the trabeculotome. The trabeculotome is then rotated through the trabecular meshwork into the anterior chamber. Classically a sector of the angle is treated, and the procedure can be repeated in another sector if needed. Western series report success rates in primary congenital/infantile and early developmental glaucoma comparable to and sometimes higher than those for goniotomy $[23,24]$. Although disease in the Middle East is often more severe and difficult to treat than in Western populations, trabeculotomy can be effective (Fig. 7); a major determinant of success is the degree of angle maldevelopment. One variation of the procedure involves use of a prolene suture rather than a trabeculotome in order to cannulate Schlemn's canal x 360 degrees and perform a 360 degree "suture" trabeculectomy, with or without illuminated microcatheter guidance $[33,34]$. Complications are typically related to intraoperative hyphema or intraoperative technique (e.g., iatrogenic crystalline lens trauma, iridodialysis). A disadvantage of trabeculotomy as compared to goniotomy is manipulation (and thus later scarring) of conjunctiva, which may make future glaucoma surgeries more difficult in the operated conjunctival quadrant.

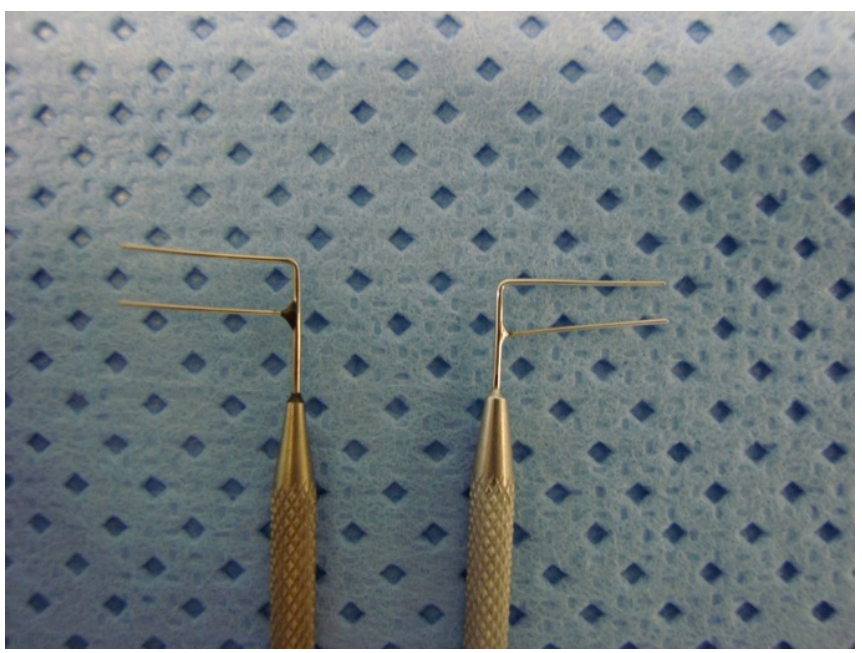

Fig. (6). (The trabeculotome): The trabeculotome-to-the-right (right) and trabeculotome-to-the-left (left) are used to rotate from within Schlemn's canal into the anterior chamber through the trabecular meshwork. Both have a slight curve (toward the background) to facilitate canalization of Schlemn's canal.

\subsection{Trabeculectomy (Penetrating Filtering Surgery)}

Trabeculectomy, the creation of an opening into the anterior chamber under a superonasal or superotemporal scleral flap, is familiar to most ophthalmologists as a common treatment for glaucomas with a well-formed anterior chamber. Failure occurs more in children than in adults [35]. Because of the rapid and robust healing response of children [36], the antimetabolite mitomycin-C is often used during pediatric trabeculectomy although its use increases the potential for complications, particularly lateronset infection [37-41]. In selected cases, some authors use post-operative suture lysis and/or the antimetabolite 5flourouracil to further modulate healing [42-44]. However, currently there are no prospective data comparing pediatric trabeculotomy with antimetabolite to pediatric trabeculotomy without antimetabolite. Factors correlated with trabeculectomy bleb failure include age less than one year and aphakia [37, 42]. The literature suggests that fornix-based flaps are superior to limbus-based flaps in children [45]. This has been my experience as well; I have found noticeably better long-term blebs (more diffuse, less ischemic, less 
(A)

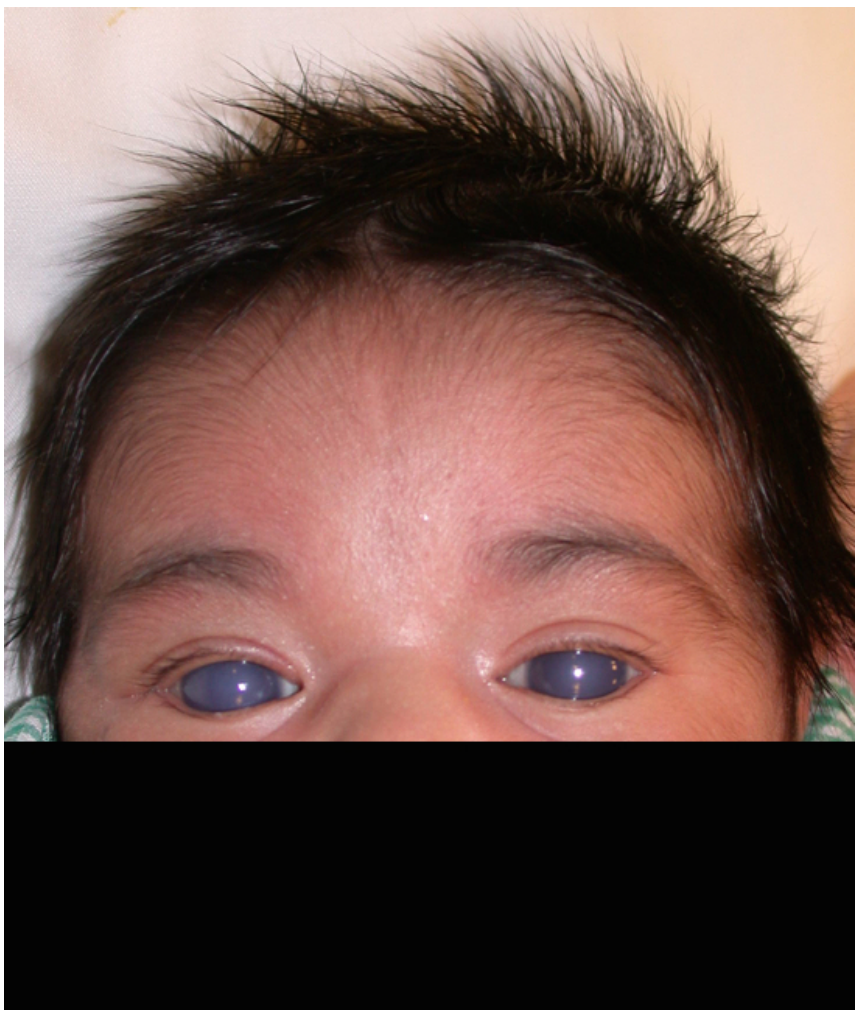

(B)

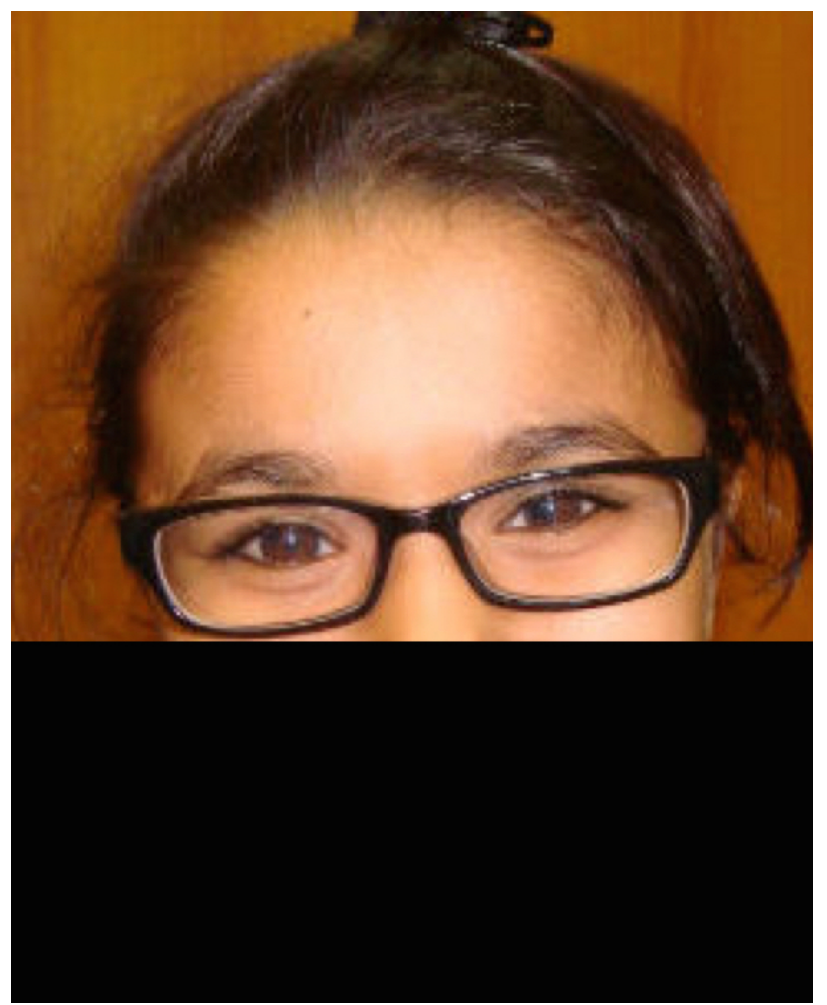

Fig. (7). (trabeculotomy): (A) This 10-day-old girl presented with classic primary congenital glaucoma. (B) 13 years after one trabeculotomy in each eye and later adjunctive ocular antihypertensive drops, she remains controlled. leakage) with fornix-based blebs (and diffusely posteriorlyapplied mitomycin-C) (Fig. 8). Because of the possibility of late-onset blebitis/endophthalmitis [37-39], all families with children that have had trabeculectomies, particularly those done that have been done with antimetabolite, need to be aware that the child should be examined immediately if red eye develops in the operated eye. Late-onset blebitis following mitomycin-C use may be more common in children than in adults [37-39]; however, as mentioned above, how the conjunctiva is dissected and how mitomycin$\mathrm{C}$ is applied is a factor in the incidence of this complication $[45,46]$. Other complications following trabeculectomy in children are similar to those of adults, such as anterior chamber shallowing, bleb leak, hypotony, suprachoroidal hemorrhage, etc. Delayed suprachoroidal hemorrhage is a rare complication in children but potentially devastating and may be more likely following mitomyocin-C use [47]. Trabeculectomy by an internal approach (using the Trabectome electrocautery system and avoiding a conjunctival incision) is a newer technique that has been used in adults and avoids complications associated with standard penetrating trabeculectomy but to date has not been studied in children [48]

\subsection{Trabeculectomy-Trabeculectomy}

Combined trabeculotomy-trabeculectomy has been advocated as an initial procedure for severe congenital/infantile glaucoma [49-53]; however, as there are no prospective data demonstrating this combined procedure to be superior to either procedure alone some ophthalmologists use trabeculotomy alone [30, 54-57] or trabeculectomy alone [49, 54, 58-60] for such cases. The combined procedure can be done with [52] or without [53] mitomycin-C. Complications are similar to those of the individual procedures alone.

\subsection{Deep Sclerectomy (Non-Penetrating Filtration Surgery)}

The anatomic goal of non-penetrating procedures such as deep sclerectomy and viscocanalostomy is to create an intrascleral space by removal of a deep scleral flap, the external wall of Schlemm's canal adjacent to trabecular meshwork, and external corneal stroma adjacent to Descemet's membrane. Aqueous humor then leaves the anterior chamber through the intact trabeculo-Descemet's membrane into the scleral space reservoir, from where it egresses into different pathways [61]. Deep sclerectomy has been used with varying degrees of success in developmental glaucoma [62,63] and seems to be a good option for uveitic glaucoma [64]. Because it is a nonpenetrating surgery the potential for complications is less; however, the procedure requires a certain degree of normal angle structure, requires a certain degree of surgical experience, and tends not to lower IOP as much as penetrating procedures. One recent study advocated combining deep sclerectomy with trabeculectomy for better results [65].

\subsection{Glaucoma Drainage Devices (Ahmed Glaucoma Valve)}

Glaucoma drainage devices are useful when angle surgery and trabeculectomy or deep sclerectomy are not good 
(A)

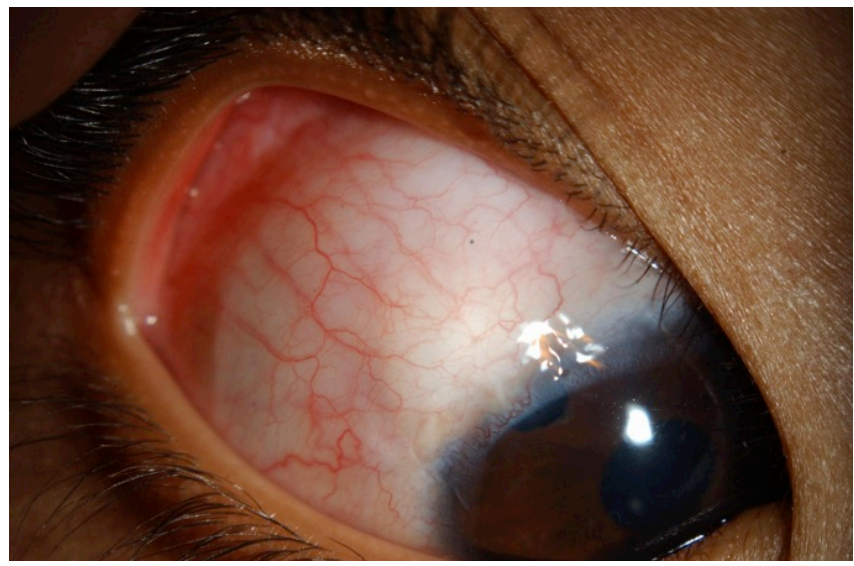

(B)

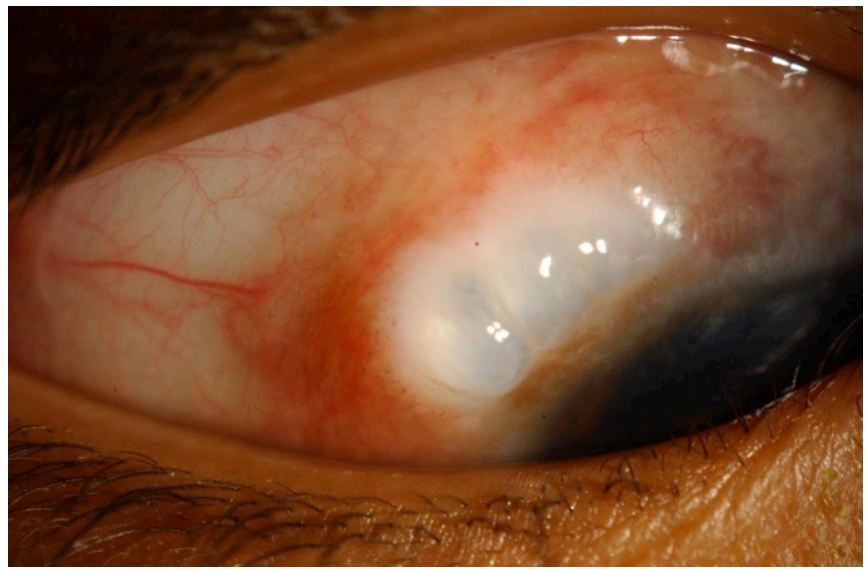

Fig. (8). (A) (Fornix-based trabeculectomy): In pediatric trabeculectomy with mitomycin-C, fornix-based flaps (and posteriorly-applied antimetabolite) tend to produce diffuser lessischemic blebs. The right eye of this 5-year-old child is approximately one year after surgery. (B) (Limbus-based trabeculectomy): In pediatric trabeculectomy with mitomycin-C, limbus-based flaps (and anteriorly-applied antimetabolite) tend to produce higher more-ischemic blebs. The right eye of this 5-yearold child is approximately one year after surgery.

options and there is a relatively clear view of the anterior chamber [66]. The Ahmed glaucoma valve (New World Medical, Inc., Rancho Cucamonga, CA) is popular in pediatrics because of its theoretical valve mechanism and the availability of smaller flexible sizes [47, 67-71]. Adjunctive ocular anti-hypertensive drops are often still needed after device implantation for IOP control. Silicone seems to be a better tolerated material than polypropylene although plate encapsulation that affects pressure control can occur with either material [69]. Tube immediately posterior to the scleral entrance site needs to be covered with a material such as pericardium or sclera to prevent tube exposure through the conjunctiva. Some ophthalmologists apply mitomycin-C to the subconjunctival region where the the plate will be implanted in an attempt to prevent thick encapsulation that can affect pressure control; however, there is no evidence that its use in children improves outcomes while there is evidence that its use in children promotes failure or complication $[47,70]$. In my experience when plate encapsulation occurs, surgically removing a portion of the encapsulation from the posterior plate can be useful. Tube retraction and anterior tube migration towards the cornea are recurrent problems in young children, the latter being particularly problematic as it can lead to exposure of the tube and infectious endophthalmitis (Fig. 9). Although one prospective study suggested Ahmed valve implantation can offer better IOP control than trabeculectomy in children less than 2 years old, approximately one-third of the implanted cases had post-operative anterior tube migration requiring intervention [72]. In our series, within 2 years postoperatively anterior tube migration occurred in $26 \%$ of eyes implanted with an Ahmed glaucoma valve before 2 years of age [71]. In my experience this complication can be minimized if care is taken to insert the tube parallel to and just anterior to the iris, just abutting the iris; at the same time I leave the tube slightly longer than would be done in adults in anticipation of some expected tube retraction. Delayed suprachoroidal hemorrhage is a rare complication following Ahmed glaucoma valve implantation in children but may be more likely following Ahmed valve implantation in pediatric aphakes [47]. Failure of the Ahmed glaucoma valve can be related to plate encapsulation as mentioned above, fibrous ingrowth [73], or, in aphakes, vitreous plugging the tube, which can occur months to years after the procedure even if anterior vitrectomy was done (Fig. 10). If a glaucoma drainage device is still functioning but further IOP control is needed despite adjunctive ocular anti-hypertensive medication, implanting a second device is an option [74]. Glaucoma drainage devices other than the Ahmed glaucoma valve have also been used successfully in children [72, 75-78]. However, newer smaller implantable glaucoma stents and shunts have not been evaluated in this patient population [79].

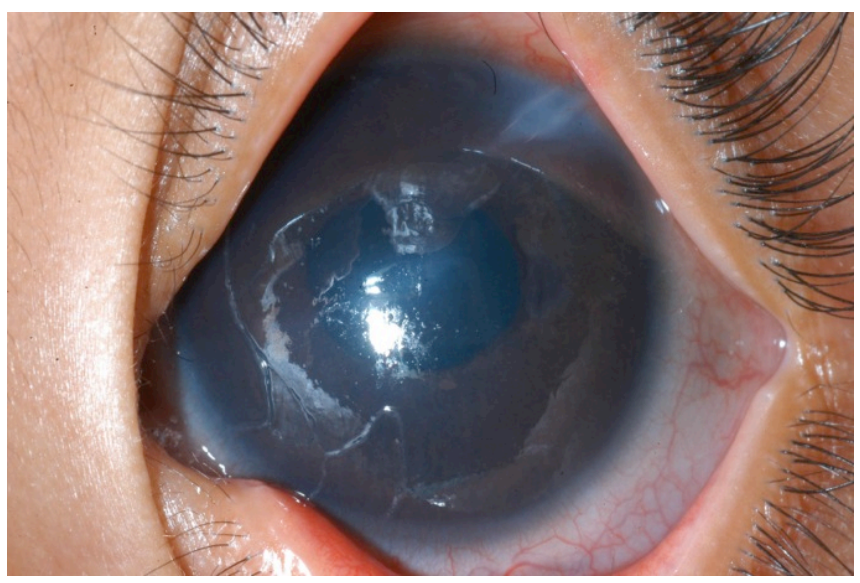

Fig. (9). (Tube into the cornea): An Ahmed glaucoma valve was implanted in the right of of a 3-year-old child such that the tube was "midway between the cornea and the iris" according to the operative note. Six months later he was referred and the tube was abutting the cornea.

\subsection{Cyclodestructive Procedures}

The major cyclodestructive procedures are cyclocryotherapy and cyclophotocoagulation, with the former rarely used since the advent of the latter. Cyclophotocoagulation typically external application by a diode laser - is a destructive procedure that historically is a procedure of last resort, although some authors advocate its earlier use [80]. 


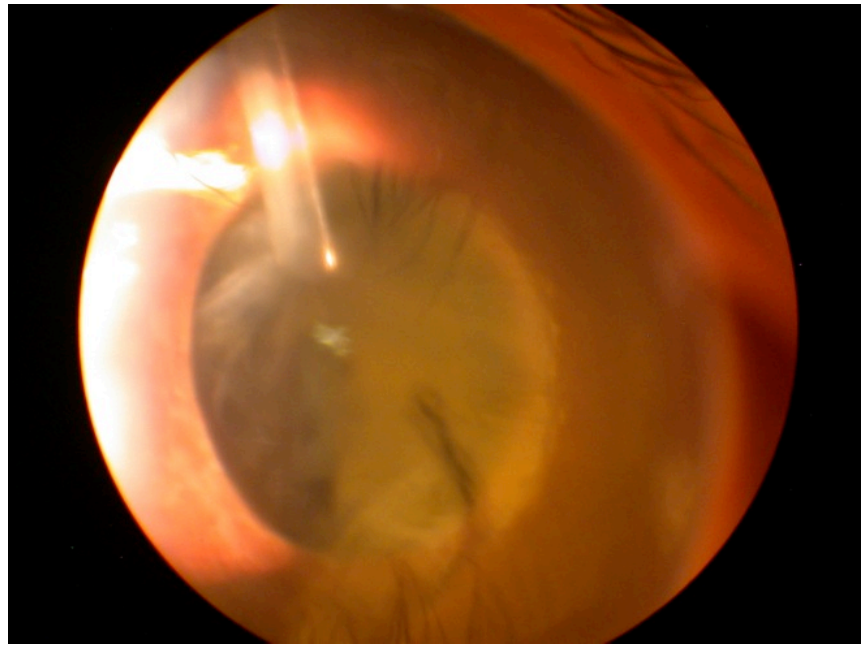

Fig. (10). (Vitreous plugging the Ahmed glaucoma valve): This 7year-old child with aphakic glaucoma presented 4 years after successful anterior vitrectomy and Ahmed glaucoma valve implantation with acutely elevated intraocular pressure and corneal edema from vitreous plugging the tube. The child did well after repeated anterior vitrectomy and secondary intraocular lens implantation.

Re-treatments are often necessary in children [80-83]. Reasons include because the ciliary epithelium of children can recover after treatment and also because the distorted anatomy of buphthalmic eyes can result in intended treatment not actually being applied to the ciliary body. Ultrasound guidance when external treatment is applied can be useful in cases of distorted anatomy [84]. Although external cyclophotocoagulation is non-incisional, postoperative complications such as phthisis, uveitis, and scleral thinning are possible, especially in buphthalmic eyes that have had multiple prior surgeries (Fig. 11) [81, 82]. Endoscopic cyclophotocoagulation seems to be a more precise technique; however, it is invasive, requires experience with the endoscope, requires an unobstructed endoscopic view of the ciliary processes, and is usually not a good option in phakic eyes [85-88].

\section{PERSONAL EXPERIENCE IN SAUDI ARABIA}

Pediatric glaucoma surgery is not "one size fits all." Prospective comparative data for surgical procedures in pediatric glaucoma are limited. There is a wide potential spectrum of disease severity, differences in pre and post operative management, and variable definitions of "success," sometimes making it difficult to draw conclusions from success rates of surgical procedures in published studies when managing a specific patient. Individual ophthalmologists need to tailor their initial (and subsequent) surgical approach according to their patient population, surgical experience, and equipment/medication availability. For example, goniotomy has a high reported success rate for congenital/infantile glaucoma in Western populations (low incidence of CYP1B1-related disease) but is inappropriate for severe cases from the Middle East (typically CYP1B1related disease). Deep sclerotomy, which may be appropriate for certain developmental cases with salvageable angle but only if the treating ophthalmologist is well-experienced with the procedure. Whether or not to use an adjunctive antimetabolite during a glaucoma surgical procedure is a moot point if the medication is not available.

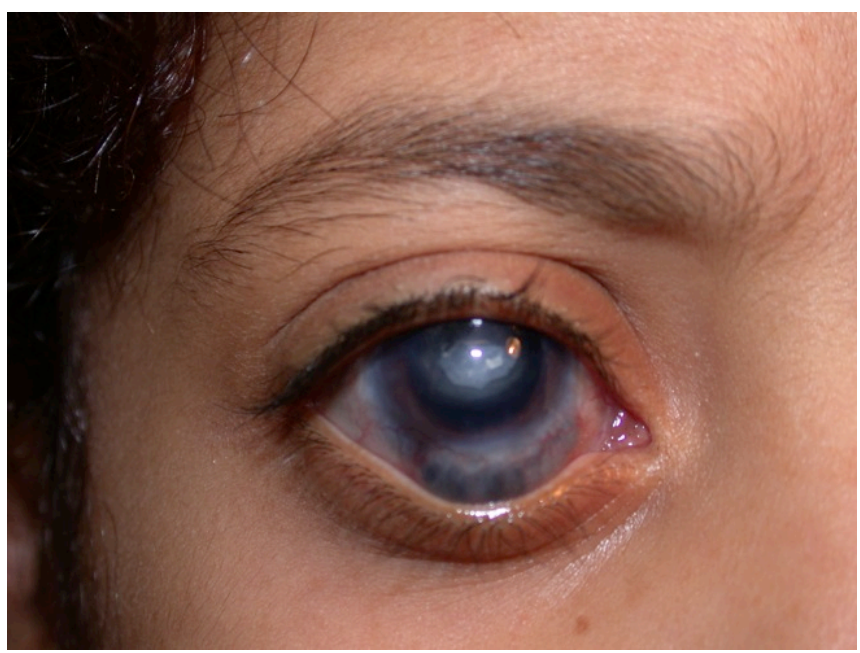

Fig. (11). (Scleral thinning after cyclophotocoagulation): Repeated external diode laser cyclophotocoagulation can be associated with scleral thinning and uveal prolapse, as was the case in the right eye of this 8-year-old girl.

My current personal algorithm for open-angle pediatric glaucoma in 2015 in Saudi Arabia, where more than $90 \%$ of primary congenital/infantile glaucoma is related to $C Y P 1 B 1$ mutations [10], is not the only or necessarily the best approach and I sometimes modify it depending on the specifics of a given patient (e.g., overall visual prognosis, ocular co-morbidities, prior procedures performed, status of the contralateral eye).

In general, my initial approach for congenital/infantile glaucoma had been trabeculotomy, performed inferotemporally so as to preserve superior conjunctiva for the future. However, more recently I have started using superior quadrant deep sclerectomy. Short-term results are encouraging, but longer follow-up is needed. In general, I do not perform trabeculectomy in children less than 10 months of age because of the high failure rate. If the congenital angle malformation seems severe or prior angle surgery or deep sclerectomy failed in an infant, my approach is to implant an Ahmed glaucoma valve, typically inferonasally (where there are no extraocular muscles) to preserve superior conjunctiva. It is important to note that some experienced ophthalmologists advocate a combined trabeculotomy-trabeculectomy (superiorly) in this setting for this patient population. If an already-implanted Ahmed glaucoma valve needs to be revised and the child is greater than 10 months of age, I may remove it and perform a different surgery. I had been performing superior quadrant fornix-based trabeculectomy with adjunctive mitomycin-C (posteriorly and diffusely, away from the limbus and the cut edge of the conjunctiva) as the success rate for the procedure improves after 10 months old. However, more recently in this setting for otherwise non-complicated cases I have been performing superior quadrant deep sclerectomy or trabeculectomy with local excision of Tenon capsule (which is the source of fibroblasts) rather than application of antimetabolite. Early results are encouraging but follow-up is only short-term thus far. 
Deep sclerectomy or trabeculectomy via a superior quadrant fornix-based approach is my procedure of choice for phakic children over 10 months of age with a cornea that allows a view of the anterior chamber and a formed anterior chamber. However, I may favor an Ahmed glaucoma valve over deep sclerectomy or trabeculectomy in such children if additional intraocular surgery is likely soon (e.g., incipient cataract), if post-operative hypotony would be high risk for suprachoroidal hemorrhage (e.g., in an eye with longstanding very high IOP or with choroidal thickening in the context of Sturge-Weber syndrome), when hygiene is a problem, or if the child has a contralateral orbital implant (which often accumulates discharge in our population- this is because of concern for potential blebitis/endophthalmitis).

For uveitic glaucoma of recent onset goniotomy is my procedure of choice; if the angle is not salvageable I would perform deep sclerectomy or trabeculectomy via a fornixbased approach or Ahmed glaucoma valve implantation.

For aphakic or pseudophakic glaucoma, I prefer endoscopic cyclophotocoagulation (with anterior vitrectomy in aphakes) but if the ciliary processes cannot be clearly visualized I tend to implant an Ahmed glaucoma valve (with anterior vitrectomy in aphakes). Using the endoscopic technique I have had the opportunity to treat several eyes that had prior external diode cyclophotocoagulation and have often found that the prior external treatments had been applied at the pars plana level rather than the level of ciliary processes, especially in buphthalmic eyes with distorted anatomy. My limited experience with endoscopic cyclophotocoagulation for pediatric phakic eyes (children treated for comfort measures only) suggests it is ineffective in pediatric phakic eyes.

External diode cyclophotocoagulation is a destructive procedure that I use sparingly as a last resort in eyes not appropriate for other surgeries with extremely poor visual potential and/or an unacceptably high risk of complication from intraocular surgery.

I cannot stress enough the need to urgently refract and evaluate the need for amblyopia treatment in pediatric glaucoma patients while they are still young. Postponing this until they are old enough to cooperate for a subjective refraction is too late and is a major cause of later untreatable visual loss (amblyopia) in children with pediatric glaucoma, even those children for whom acceptable IOPs are achieved and maintained following surgery.

\section{CONFLICT OF INTEREST}

The author confirms that this article content has no conflict of interest.

\section{ACKNOWLEDGEMENTS}

Declared none.

\section{REFERENCES}

[1] Hoskins HD Jr, Shaffer RN, Hetherington J. Anatomical classification of the developmental glaucomas. Arch Ophthalmol 1984; 102(9): 1331-6.

[2] Beck AD. Diagnosis and management of pediatric glaucoma. Ophthalmol Clin North Am 2001; 14(3): 501-12.
[3] Idrees F, Vaideanu D, Fraser SG, Sowden JC, Khaw PT. A review of anterior segment dysgeneses. Surv Ophthalmol 2006; 51(3): 213-31.

[4] Yeung HH, Walton DS. Clinical classification of childhood glaucomas. Arch Ophthalmol 2010; 128(6): 680-4.

[5] Ganesh A, Mai DT, Levin AV. Pediatric glaucoma terminology. Am J Med Genet A 2013; 161A(12): 3205-15.

[6] Beck A, Chang TCP, Freeman S. Definition, classification, differential diagnosis. In: Weinreb RN, Grajewski A, Papadopoulos M, Grigg J, Freedman F, Eds. Childhood glaucoma. WGA consensus series - 9. Amsterdam: Kugler Publications 2013; pp. 310

[7] Khan AO, Aldahmesh MA, Mohamed JY, Alkuraya FS. Corneal enlargement without optic disk cupping in children with recessive CYP1B1 mutations. J AAPOS 2013; 17(6): 643-5.

[8] Khan AO. Conditions that can be mistaken as early childhood glaucoma. Ophthalmic Genet 2011; 32(3): 129-37.

[9] Khan AO, Al-Shehah A, Ghadhfan FE. High measured intraocular pressure in children with recessive congenital hereditary endothelial dystrophy. J Pediatr Ophthalmol Strabismu 2010; 47(1): 29-33

[10] Khan AO. Genetics of primary glaucoma. Curr Opin Ophthalmol 2011; 22(5): 347-55

[11] Khan AO, Aldahmesh MA, Al-Abdi L, et al. Molecular characterization of newborn glaucoma including a distinct aniridic phenotype. Ophthalmic Genet 2011; 32(3): 138-42.

[12] Khan AO, Aldahmesh MA, Alkuraya FS. Congenital megalocornea with zonular weakness and childhood lens-related secondary glaucoma - a distinct phenotype caused by recessive LTBP2 mutations. Mol Vis 2011; 17: 2570-9.

[13] Ho CL, Walton DS. Primary congenital glaucoma: 2004 update. J Pediatr Ophthalmol Strabismus 2004; 41(5): 271, 88; quiz 300-1.

[14] Al-Harthi E, Al-Shahwan S, Al-Turkmani S, Khan AO. Retinal detachment and congenital glaucoma. Ophthalmology 2007; 114(8): 1590-1.

[15] Khan AO, Aldahmesh MA, Al-Amri A. Heterozygous FOXC1 mutation $(\mathrm{M} 161 \mathrm{~K})$ associated with congenital glaucoma and aniridia in an infant and a milder phenotype in her mother. Ophthalmic Genet 2008; 29(2): 67-71.

[16] Barkan O. A new operation for chronic glaucoma (restoration of physiological function by opening Schlemm's canal under direct magnified vision). Am J Ophthalmol 1936; 19: 951-66.

[17] Medow NB, Sauer HL. Endoscopic goniotomy for congenital glaucoma. J Pediatr Ophthalmol Strabismus 1997; 34(4): 258-9.

[18] Joos KM, Shen JH. An ocular endoscope enables a goniotomy despite a cloudy cornea. Arch Ophthalmol 2001; 119(1): 134-5.

[19] Kulkarni SV, Damji KF, Fournier AV, Pan I, Hodge WG. Endoscopic goniotomy: early clinical experience in congenital glaucoma. J Glaucoma 2010; 19(4): 264-9.

[20] Ho CL, Wong EY, Walton DS. Goniosurgery for glaucoma complicating chronic childhood uveitis. Arch Ophthalmol 2004; 122(6): 838-44.

[21] Barkan O. Surgery of congenital glaucoma; review of 196 eyes operated by goniotomy. Am J Ophthalmol 1953; 36(11): 1523-34.

[22] Shaffer RN. Prognosis of goniotomy in primary infantile glaucoma (trabeculodysgenesis). Trans Am Ophthalmol Soc 1982; 80: 321-5. McPherson SD. Jr, Berry DP. Goniotomy $v s$ external trabeculotomy for developmental glaucoma. Am J Ophthalmol 1983; 95(4): 427-31.

[24] Anderson DR. Trabeculotomy compared to goniotomy for glaucoma in children. Ophthalmology 1983; 90(7): 805-6.

[25] Bothun ED, Guo Y, Christiansen SP, et al. Outcome of angle surgery in children with aphakic glaucoma. J AAPOS 2010; 14(3): 235-9.

[26] Yeung HH, Walton DS. Goniotomy for juvenile open-angle glaucoma. J Glaucoma 2010; 19(1): 1-4

[27] Chen TC, Walton DS. Goniosurgery for prevention of aniridic glaucoma. Arch Ophthalmol 1999; 117(9): 1144-8.

[28] Senft SH, Tomey KF, Traverso CE. Neodymium-YAG laser goniotomy $v s$ surgical goniotomy. A preliminary study in paired eyes. Arch Ophthalmol 1989; 107(12): 1773-6.

[29] Burian HM. A case of Marfan's syndrome with bilateral glaucoma with description of a new type of operation for developmental glaucoma (trabeculotomy ab externo). Am J Ophthalmol 1960; 50: $1187-92$. 
[30] Debnath SC, Teichmann KD, Salamah K. Trabeculectomy versus trabeculotomy in congenital glaucoma. Br J Ophthalmol 1989; 73(8): 608-11.

[31] Bejjani BA, Lewis RA, Tomey KF, et al. Mutations in CYP1B1, the gene for cytochrome $\mathrm{P} 4501 \mathrm{~B} 1$, are the predominant cause of primary congenital glaucoma in saudi arabia. Am J Hum Genet 1998; 62(2): 325-33.

[32] Al-Hazmi A, Awad A, Zwaan J, Al-Mesfer SA, Al-Jadaan I, AlMohammed A. Correlation between surgical success rate and severity of congenital glaucoma. Br J Ophthalmol 2005; 89(4): 449-53.

[33] Beck AD, Lynch MG. 360 degrees trabeculotomy for primary congenital glaucoma. Arch Ophthalmol 1995; 113(9): 1200-2.

[34] Sarkisian SR Jr. An illuminated microcatheter for 360-degree trabeculotomy [corrected] in congenital glaucoma: a retrospective case series. J AAPOS 2010; 14(5): 412-6.

[35] Gressel MG, Heuer DK, Parrish RK II. Trabeculectomy in young patients. Ophthalmol 1984; 91(10): 1242-6.

[36] Beauchamp GR, Parks MM. Filtering surgery in children: barriers to success. Ophthalmology 1979; 86(1): 170-80.

[37] Waheed S, Ritterband DC, Greenfield DS, Liebmann JM, Sidoti PA, Ritch R. Bleb-related ocular infection in children after trabeculectomy with mitomycin C. Ophthalmology 1997; 104(12): 2117-20.

[38] Beck AD, Wilson WR, Lynch MG, Lynn MJ, Noe R. Trabeculectomy with adjunctive mitomycin $\mathrm{C}$ in pediatric glaucoma. Am J Ophthalmol 1998; 126(5): 648-57.

[39] al-Hazmi A, Zwaan J, Awad A, al-Mesfer S, Mullaney PB, Wheeler DT. Effectiveness and complications of mitomycin C use during pediatric glaucoma surgery. Ophthalmology 1998; 105(10): 1915-20.

[40] Sidoti PA, Belmonte SJ, Liebmann JM, Ritch R. Trabeculectomy with mitomycin-C in the treatment of pediatric glaucomas. Ophthalmology 2000; 107(3): 422-9.

[41] Beck AD, Freedman SF. Trabeculectomy with mitomycin-C in pediatric glaucomas. Ophthalmology 2001; 108(5): 835-7.

[42] Freedman SF, McCormick K, Cox TA. Mitomycin C-augumented trabeculectomy with postoperative wound modulation in pediatric glaucoma. J AAPOS 1999; 3(2): 117-24.

[43] Snir M, Lusky M, Shalev B, Gaton D, Weinberger D. Mitomycin C and 5-fluorouracil antimetabolite therapy for pediatric glaucoma filtration surgery. Ophthalmic Surg Lasers 2000; 31(1): 31-7.

[44] Low S, Hamada S, Nischal KK. Antimetabolite and releasable suture augmented filtration surgery in refractory pediatric glaucomas. J AAPOS 2008; 12(2): 166-72.

[45] Wells AP, Cordeiro MF, Bunce C, Khaw PT. Cystic bleb formation and related complications in limbus- versus fornix-based conjunctival flaps in pediatric and young adult trabeculectomy with mitomycin C. Ophthalmology 2003; 110(11): 2192-7.

[46] Khaw PT, Chiang M, Shah P, Sii F, Lockwood A, Khalili A. Enhanced trabeculectomy: the Moorfields safer surgery system. Dev Ophthalmol 2012; 50: 1-28.

[47] Ghadhfan FE, Khan AO. Delayed suprachoroidal hemorrhage after pediatric glaucoma surgery. J AAPOS 2009; 13(3): 283-6.

[48] Minckler D, Mosaed S, Dustin L, Ms BF. Trabectome Study Group. Trabectome (trabeculectomy-internal approach): additional experience and extended follow-up. Trans Am Ophthalmol Soc 2008; 106: 149-59.

[49] Luntz MH. Congenital, infantile, and juvenile glaucoma. Ophthalmology 1979; 86(5): 793-802.

[50] Elder MJ. Combined trabeculotomy-trabeculectomy compared with primary trabeculectomy for congenital glaucoma. Br J Ophthalmol 1994; 78(10): 745-8.

[51] Mandal AK, Naduvilath TJ, Jayagandan A. Surgical results of combined trabeculotomy-trabeculectomy for developmental glaucoma. Ophthalmology 1998; 105(6): 974-82.

[52] Mullaney PB, Selleck C, Al-Awad A, Al-Mesfer S, Zwaan J. Combined trabeculotomy and trabeculectomy as an initial procedure in uncomplicated congenital glaucoma. Arch Ophthalmol 1999; 117(4): 457-60.

[53] Mandal AK, Gothwal VK, Nutheti R. Surgical outcome of primary developmental glaucoma: a single surgeon's long-term experience from a tertiary eye care centre in India. Eye (Lond) 2007; 21(6): 764-74.
[54] Biedner BZ, Rothkoff L. Combined trabeculotomy-trabeculectomy compared with primary trabeculotomy for congenital glaucoma. J Pediatr Ophthalmol Strabismus 1998; 35(1): 49-50.

[55] Dietlein TS, Jacobi PC, Krieglstein GK. Prognosis of primary ab externo surgery for primary congenital glaucoma. Br J Ophthalmol 1999; 83(3): 317-22.

[56] Meyer G, Schwenn O, Pfeiffer N, Grehn F. Trabeculotomy in congenital glaucoma. Graefes Arch Clin Exp Ophthalmol 2000; 238(3): 207-13.

[57] Khan AO. Trabeculotomy versus trabeculotomy-trabeculectomy for congenital glaucoma. Br J Ophthalmol 2006; 90(1): 125.

[58] Luntz MH, Livingston DG. Trabeculotomy $a b$ externo and trabeculectomy in congenital and adult-onset glaucoma. Am J Ophthalmol 1977; 83(2): 174-9.

[59] Burke JP, Bowell R. Primary trabeculectomy in congenital glaucoma. Br J Ophthalmol 1989; 73(3): 186-90.

[60] Fulcher T, Chan J, Lanigan B, Bowell R, O'Keefe M. Long-term follow up of primary trabeculectomy for infantile glaucoma. $\mathrm{Br} \mathrm{J}$ Ophthalmol 1996; 80(6): 499-502.

[61] Mendrinos E, Mermoud A, Shaarawy T. Nonpenetrating glaucoma surgery. Surv Ophthalmol 2008; 53(6): 592-630.

[62] Luke C, Dietlein TS, Jacobi PC, Konen W, Krieglstein GK. Risk profile of deep sclerectomy for treatment of refractory congenital glaucomas. Ophthalmology 2002; 109(6): 1066-71.

[63] Al-Obeidan SA, Osman E, Dewedar AS, Kestelyn P, Mousa A. Efficacy and safety of deep sclerectomy in childhood glaucoma in Saudi Arabia. Acta Ophthalmol 2014; 92(1): 65-70.

[64] Al Obeidan SA, Osman EA, Al-Muammar AM, Abu El-Asrar AM. Efficacy and safety of deep sclerectomy in uveitic glaucoma. Int Ophthalmol 2009; 29(5): 367-72.

[65] Feusier M, Roy S, Mermoud A. Deep sclerectomy combined with trabeculectomy in pediatric glaucoma. Ophthalmology 2009; 116(1): 30-8

[66] Tanimoto SA, Brandt JD. Options in pediatric glaucoma after angle surgery has failed. Curr Opin Ophthalmol 2006; 17(2): 132-7.

[67] Coleman AL, Smyth RJ, Wilson MR, Tam M. Initial clinical experience with the Ahmed glaucoma valve implant in pediatric patients. Arch Ophthalmol 1997; 115(2): 186-91.

[68] Chen TC, Bhatia LS, Walton DS. Ahmed valve surgery for refractory pediatric glaucoma: a report of 52 eyes. J Pediatr Ophthalmol Strabismus 2005; 42(5): 274-83; quiz 304-5.

[69] Khan AO, Al-Mobarak F. Comparison of polypropylene and silicone Ahmed valve survival 2 years following implantation in the first 2 years of life. Br J Ophthalmol 2009; 93(6): 791-4.

[70] Al-Mobarak F, Khan AO. Two-year survival of Ahmed valve implantation in the first 2 years of life with and without intraoperative mitomycin-C. Ophthalmology 2009; 116(10): 18625.

[71] Al-Mobarak F, Khan AO. Complications and 2-year valve survival following Ahmed valve implantation during the first 2 years of life. Br J Ophthalmol 2009; 93(6): 795-8

[72] Beck AD, Freedman S, Kammer J, Jin J. Aqueous shunt devices compared with trabeculectomy with mitomycin-C for children in the first two years of life. Am J Ophthalmol 2003; 136(6): 9941000 .

[73] Trigler L, Proia AD, Freedman SF. Fibrovascular ingrowth as a cause of Ahmed glaucoma valve failure in children. Am J Ophthalmol 2006; 141(2): 388-9.

[74] Tung I, Marcus I, Thiamthat W, Freedman SF. Second glaucoma drainage devices in refractory pediatric glaucoma: failure by fibrovascular ingrowth. Am J Ophthalmol 2014; 158(1): 113-7.

[75] Netland PA, Walton DS. Glaucoma drainage implants in pediatric patients. Ophthalmic Surg 1993; 24(11): 723-9.

[76] Rodrigues AM, Corpa MV, Mello PA, de Moura CR. Results of the Susanna implant in patients with refractory primary congenital glaucoma. J AAPOS 2004; 8(6): 576-9.

[77] Rolim de Moura C, Fraser-Bell S, Stout A, Labree L, Nilfors M, Varma R. Experience with the Baerveldt glaucoma implant in the management of pediatric glaucoma. Am J Ophthalmol 2005; 139(5): 847-54.

[78] Autrata R, Helmanova I, Oslejskova H, Vondracek P, Rehurek J. Glaucoma drainage implants in the treatment of refractory glaucoma in pediatric patients. Eur J Ophthalmol 2007; 17(6): 92837 . 
[79] Francis BA, Singh K, Lin SC, et al. Novel glaucoma procedures: a report by the American Academy of Ophthalmology. Ophthalmology 2011; 118(7): 1466-80.

[80] Kraus CL, Tychsen L, Lueder GT, Culican SM. Comparison of the effectiveness and safety of transscleral cyclophotocoagulation and endoscopic cyclophotocoagulation in pediatric glaucoma. J Pediatr Ophthalmol Strabismus 2014; 51(2): 120-7.

[81] Bock CJ, Freedman SF, Buckley EG, Shields MB. Transscleral diode laser cyclophotocoagulation for refractory pediatric glaucomas. J Pediatr Ophthalmol Strabismus 1997; 34(4): 235-9.

[82] Kirwan JF, Shah P, Khaw PT. Diode laser cyclophotocoagulation: role in the management of refractory pediatric glaucomas. Ophthalmology 2002; 109(2): 316-23.

[83] Barkana Y, Morad Y, Ben-nun J. Endoscopic photocoagulation of the ciliary body after repeated failure of trans-scleral diode-laser cyclophotocoagulation. Am J Ophthalmol 2002; 133(3): 405-7.
[84] Way AL, Nischal KK. High-frequency ultrasound-guided transscleral diode laser cyclophotocoagulation. Br J Ophthalmol 2014; 98(7): 992-4.

[85] Plager DA, Neely DE. Intermediate-term results of endoscopic diode laser cyclophotocoagulation for pediatric glaucoma. J AAPOS 1999; 3(3): 131-7.

[86] Neely DE, Plager DA. Endocyclophotocoagulation for management of difficult pediatric glaucomas. J AAPOS 2001; 5(4): 221-9.

[87] Carter BC, Plager DA, Neely DE, Sprunger DT, Sondhi N, Roberts GJ. Endoscopic diode laser cyclophotocoagulation in the management of aphakic and pseudophakic glaucoma in children. J AAPOS 2007; 11(1): 34-40.

[88] Al-Haddad CE, Freedman SF. Endoscopic laser cyclophotocoagulation in pediatric glaucoma with corneal opacities. J AAPOS 2007; 11(1): 23-8.

Received: March 28, 2015

Revised: March 30, 2015

Accepted: March 30, 2015

(C) Arif O. Khan; Licensee Bentham Open.

This is an open access article licensed under the terms of the Creative Commons Attribution Non-Commercial License (http://creativecommons.org/licenses/by-nc/3.0/) which permits unrestricted, non-commercial use, distribution and reproduction in any medium, provided the work is properly cited. 